\title{
Sociodemographic profile and stages of Parkinson's disease associated with predictors of Temporomandibular Disorder
}

Jonatas Silva de Oliveira1
https://orcid.org/0000-0001-5704-5427

Amanda do Vale Sobral ${ }^{1}$

https://orcid.org/0000-0002-4538-1172

Taysa Vannoska de Almeida Silva ${ }^{2}$

https://orcid.org/0000-0003-0517-2410

Maria das Graças Wanderley de Sales Coriolano²

https://orcid.org/0000-0002-7937-7761

Carla Cabral dos Santos Accioly Lins ${ }^{2}$ https://orcid.org/0000-0002-1018-5331

Universidade Federal de Pernambuco UFPE, Curso de Graduação de Odontologia, Recife, Pernambuco, Brasil. Universidade Federal de Pernambuco, Programa de Pós-Graduação em Gerontologia, Recife, Pernambuco, Brasil.

Research support source: Coordenação de Aperfeiçoamento de Pessoal de Nível Superior - Brasil (CAPES) - Finance Code 001.

Conflict of interests: Nonexistent

\section{(c) (i)}

Received on: September 17, 2020 Accepted on: December 14, 2020

Corresponding address:

Carla Cabral dos Santos Accioly Lins Programa de Pós-Graduação em

Gerontologia, Universidade Federal de Pernambuco - UFPE

Avenida Professor Moraes Rego, 1235,

Cidade Universitária

CEP: 50670-90 - Recife, Pernambuco,

Brasil

E-mail: carla.santos@ufpe.br

\section{ABSTRACT}

Purpose: to analyze the predictors of temporomandibular disorder in people with Parkinson's disease, verifying their associations with sociodemographic aspects and stages of the disease.

Methods: a study based on secondary data from research conducted in 2017 with 110 people with Parkinson's disease. They were assessed with the Research Diagnostic Criteria for Temporomandibular Disorders and the Parkinson's disease staging scale. The studied predictive variables for temporomandibular disorder were pain, crepitation, clicking, nighttime and daytime clenching/gnashing, uncomfortable/non-habitual bite, morning rigidity, and tinnitus. The sociodemographic aspects assessed were age, sex, schooling level, marital status, income, and stages 1 to 3 of the disease. The chisquared odds ratio was used with a $95 \%$ confidence interval and significance level at $p<0.05$.

Results: an association was verified between nighttime clenching/gnashing and income $(p=0.006)$; tinnitus and income range from $1 / 2$ to $3(p=0.003)$ and from 4 to 10 minimum wages $(p=0.004)$; and between tinnitus and stage $1(p=0.02)$.

Conclusion: this study verified that the predictors associated with temporomandibular disorder in people with Parkinson's disease were pain, clicking, crepitation, uncomfortable/non-habitual bite, and morning rigidity. It was verified that income and stage 1 of the disease had an association with nighttime clenching/gnashing and tinnitus.

Keywords: Parkinson's Disease; Craniomandibular Disorders; Temporomandibular Joint Disorders; Facial Pain; Muscle Rigidity 


\section{INTRODUCTION}

Aging is characterized by complex biological and psychosocial related changes, which directly interfere with the older person's health. This process may bring about greater health care needs; hence, the health systems need to be multiprofessional to ensure this population's well-being'. As the years go by, neurological diseases are more likely to appear because of molecular losses in the nervous system, and they can manifest in various ways. These include Parkinson's disease $(P D)^{2,3}$, a degenerative clinical syndrome that progressively leads to the death of substantia nigra dopaminergic neurons in the central nervous system. $\mathrm{PD}$, the second most common neurologic disorder in older adults, manifests motor symptoms such as bradykinesia, tremor at rest, postural instability, and rigidity ${ }^{4}$. The Hoehn and Yahr scale classifies it into five stages, each one with progressive manifestations indicating the patient's general status ${ }^{5}$.

PD changes the neck posture ${ }^{6}$, which may also change the biomechanics of the temporomandibular joint (TMJ) and trigger the temporomandibular disorder $(\mathrm{TMD})^{7}$. This is a complex musculoskeletal disorder affecting the temporomandibular joint, muscles, and structures associated with the stomatognathic system, causing functional disorders ${ }^{8,9}$.

TMD, with its multifactorial etiology, is a pathology related to psychological factors, occlusal changes, and parafunctional habits. It also causes symptoms such as pain, headache, limited mouth opening, and tinnitus ${ }^{10,11}$. The psychosocial factors related to TMD may cause the person stress and consequently pain ${ }^{12,13}$. These conditions can be assessed with questionnaires and examinations that associate pertaining characteristics to diagnose the disorder, aiding both the researcher and clinician. The gold-standard to diagnose TMD is the Research Diagnostic Criteria for Temporomandibular Disorders (RDC/TMD). It has a biaxial approach, enabling physical findings to be measured in Axis I, and the psychosocial status, depression, and anxiety to be assessed in Axis II. It encompasses research fundamental elements that allow its replication in different studies $^{14}$. The new questionnaire Diagnostic Criteria for TMD (DC/TMD) has since recently been used to detect the temporomandibular disorder ${ }^{15}$.

A recent study pointed out the factors associated with TMD in older adults, namely: being female, having a low income, tinnitus, dizziness, depression, headache, or bruxism, missing teeth, and wearing complete dentures ${ }^{10}$. Moreover, pain, clicking, and crepitation have already been verified as factors associated with $T M D$ in people with $\mathrm{PD}^{16}$. Hence, this study aimed to analyze the predictors of TMD in people with $\mathrm{PD}$, verifying their association with sociodemographic aspects and stages of the disease to furnish further information in this field of knowledge.

\section{METHODS}

This is a cross-sectional study with secondary data obtained from the research entitled: "Influence of the temporomandibular disorder on bite strength and electrical activity of the masticatory muscles in people with Parkinson's disease", approved in the Research Ethics Committee (REC) of the Universidade Federal de Pernambuco - UFPE (Federal University of Pernambuco), Brazil, under evaluation report no. 1.763.512. The research, comprising 110 individuals who signed the informed consent form, was conducted in 2017 at a public university hospital and the Parkinson Association of Pernambuco.

The inclusion criteria were established as 1) Clinical diagnosis of idiopathic PD, being in stages 1 to 3 in the global classification scale of the disease; 2) Being under the effect of the antiparkinsonian drug; 3) Having natural teeth or wearing partial or complete dentures; 4) Not being disoriented and being taken care of by the family. The exclusion criteria: 1) Having other neurologic diseases associated with PD; 2) Being cognitively impaired, as assessed with the mini-mental state examination (MMSE); 3) Lacking teeth in both dental arches and/or not wearing dentures; 4) Being incapable of communicating verbally to answer the questionnaire in the interview.

The cognitive function was assessed with the MMSE, an instrument with 11 items and a maximum score of 30 points. The cutoff depends on the person's schooling level - illiterates: 13 points; low schooling: 18 points; 8 or more years at school: 26 points ${ }^{17}$.

The predictive variables assessed in the study were pain, clicking, crepitation, nighttime and daytime clenching/gnashing, uncomfortable/non-habitual bite, morning rigidity, and tinnitus. They were obtained with the RDC/TMD.

The RDC/TMD has a biaxial approach, enabling the physical findings to be measured in Axis I, and the psychosocial status to be assessed in Axis $\|^{18}$. The diagnoses of the physical examinations in Axis I are divided into three groups: Group I - Muscle diagnoses (myofascial pain with limited TMJ opening); Grupo II Disc displacements (disc displacement with reduction, 
disc displacement without reduction and with a limited opening, and disc displacement without reduction and without limited opening); and Group III - Arthralgia, arthritis, arthrosis (arthralgia, TMJ osteoarthritis, and TMJ osteoarthrosis). Hence, a single person can have multiple diagnoses. The psychosocial status assessment, Axis II, provides a profile of chronic painful disorder (depression, anxiety, and the relationship between these factors and other physical symptoms), generated from the answers to its 30 questions. The findings obtained in Axis II serve as a basis for the diagnoses referred to in Axis I. However, as a rule, each person can receive no more than one muscle diagnosis from Group I, and one diagnosis from Group II and one from Group III for each side. The diagnoses in each of the groups are mutually exclusive. This means that, in principle, a person can receive from zero (no diagnosable conditions) to five diagnoses (a muscle diagnosis, plus one from Group II and one from Group III for each side) $)^{14}$.

The data was collected by a team made up of dental surgeons and physical therapists, who were trained and leveled by specialists in the field. Due to the nature of the questionnaire, all the questions were read in an interview, following always the same sequence along with their possible answers.

The sociodemographic data collected with the RDC/ TMD were age (considering their last birthday in relation to the date of data collection), sex (male or female), schooling level (completed years at school - illiterates: 0 years; elementary school: 1 to 4 years; middle school: 5 to 8 years; high school: 9 to 11 years; higher education: 12 or more years), marital status (married, single, widowed, divorced, cohabiting, separated, and never married), monthly income (in minimum wages, divided into groups: $1 / 2$ to 3 ; 4 to $10 ; 11$ to 20 ; not informed.

The PD signs and symptoms were classified with the original version of the Hoehn and Yahr scale, which has five classification stages to assess the severity of PD. In stage 1 - the patients have unilateral manifestations and can live independently; stage 2 - bilateral manifestations combined with possible speech abnormalities, flexed posture, and abnormal gait; stage 3 - bilateral worsening of the PD manifestations, besides balance disorders, though still capable of living independently. Stages 4 and 5 are severer forms of the disease, in which the patients need a lot of support (stage 4) or are bedridden or wheelchair-ridden (stage 5$)^{5}$.

\section{Statistical analysis}

Descriptive statistics and frequency counts were used to characterize the sample. It was stratified by TMD diagnosis to study the association with the sociodemographic variables, assessing the association between each possible pair of predictive variables. The chi-squared $\left(X^{2}\right)$ odds ratio $(O R)$ with $95 \%$ confidence interval $(\mathrm{Cl})$ was applied to the analysis, which was conducted in the Statistica 13.2 software, with a 0.05 significance level.

Analyses of sensitivity, specificity, positive predictive value (PPV), negative predictive value (NPV), and degree of agreement with the kappa coefficient were employed to assess the accuracy of the variables in relation to the TMD diagnosis.

Sensitivity was established as the capacity of the clinical characteristics (pain, clicking, and crepitation) to correctly identify people with TMD, whereas specificity was the variables' capacity to dismiss TMD when it was absent. Different from sensitivity and specificity, the PPV and NPV depend on the prevalence of the disorder in the sample. The PPV indicates the proportion of people with TMD among those who had a positive result in the variables test, while NPV is the proportion of healthy people (without TMD) among those who had a negative result in the predictive variables test. Hence, the higher the prevalence of the disease in the tested sample, the higher the PPV and the lower the NPV. Inversely, the lower the prevalence of the disease in the tested sample, the lower the PPV and the higher the NPV ${ }^{19}$.

The degree of agreement between the studied variables and the TMD diagnosis was assessed with the kappa coefficient, an association measure used to describe and test the degree of agreement (reliability and precision) in the classification of the disorder. The different levels of agreement are < 0 : No agreement; 0 - 0.20: Minimum agreement; 0.21 - 0.40: Fair agreement; $0.41-0.60$ : Moderate agreement; 0.61 - 0.80: Substantial agreement; $0.81-1.0$ : Perfect agreement ${ }^{20}$.

\section{RESULTS}

In this study, $65 \%$ of the sample were males, with a prevalence of $63 \%$ in the age group older than 60 years, and $30 \%$ had completed high school. Also, $67 \%$ were married, $74 \%$ had an income of $1 / 2$ to 3 minimum wages, $54 \%$ were in stage 2 , and the mean time since disease onset was 7 years (Table 1). TMD 
was observed in $35 \%$ of the people with PD $(n=38)$. The predictors were distributed as follows: pain (15\%); clicking (34\%); crepitation (24\%); nighttime clenching/ gnashing (24\%); daytime clenching/gnashing (18\%); uncomfortable/non-habitual chewing (47\%); morning rigidity (15\%); tinnitus (45\%).

Table 1. Sample characterization, according to sociodemographic data and Parkinson's disease staging

\begin{tabular}{|c|c|c|c|}
\hline Variables & $\mathrm{N}=110$ & $(\%)$ & Mean \pm Standard deviation \\
\hline Age & & & $63 \pm 9$ \\
\hline Less than 60 years & 41 & $37 \%$ & \\
\hline More than 60 years & 69 & $63 \%$ & \\
\hline \multicolumn{4}{|l|}{ Sex } \\
\hline Males & 72 & $65 \%$ & \\
\hline Females & 38 & $35 \%$ & \\
\hline Schooling (years) & & & $9 \pm 5$ \\
\hline Illiterate & 3 & $3 \%$ & \\
\hline Elementary School (1-4 years) & 24 & $22 \%$ & \\
\hline Middle School (5-8 years) & 27 & $24 \%$ & \\
\hline High School (9-11 years) & 33 & $30 \%$ & \\
\hline Higher Education (12-17 years) & 23 & $21 \%$ & \\
\hline \multicolumn{4}{|l|}{ Marital Status } \\
\hline Married & 74 & $67 \%$ & \\
\hline Single & 3 & $3 \%$ & \\
\hline Widowed & 11 & $10 \%$ & \\
\hline Divorced & 4 & $4 \%$ & \\
\hline Cohabiting & 11 & $10 \%$ & \\
\hline Separated & 3 & $3 \%$ & \\
\hline Never married & 3 & $3 \%$ & \\
\hline \multicolumn{4}{|l|}{ Income (MW) } \\
\hline $1 / 2$ to 3 & 81 & $74 \%$ & \\
\hline 4 to 10 & 30 & $30 \%$ & \\
\hline 11 to 20 & 3 & $3 \%$ & \\
\hline $\mathrm{NI}$ & 3 & $3 \%$ & \\
\hline \multicolumn{4}{|l|}{ Stage of the disease } \\
\hline 1 & 27 & $24 \%$ & \\
\hline 2 & 59 & $54 \%$ & \\
\hline 3 & 24 & $22 \%$ & \\
\hline Time since diagnosis of PD (years) & & & $7 \pm 4$ \\
\hline
\end{tabular}

Captions: PD - Parkinson's disease; MW - minimum wages per month; NI: Not informed 
In the association between TMD and the studied variables, there was a significance with pain $(p=0.000)$, clicking ( $p=0.000)$, crepitation $(p=0.002)$, uncomfortable/non-habitual bite $(p=0.048)$, and morning rigidity $(p=0.028)$. An oscillation was perceived in the odds ratio result - pain was the predictor with the highest value $(\mathrm{OR}=13.41)$, while uncomfortable/ non-habitual bite was the lowest $(\mathrm{OR}=2.27)$. Among these predictors, the specificity values were higher than those of sensitivity - except for uncomfortable/ non-habitual bite, in which the values were inverted. Observing the NPV and PPV values, pain had a higher value (PPV $=82 \%$ ) than the others. The kappa values oscillated between the variables; the higher value for clicking (kappa $=0.45$ ) indicated fair agreement (Table 2).

Table 2. Predictors of the temporomandibular disorder in people with Parkinson's disease

\begin{tabular}{|c|c|c|c|c|}
\hline Pain & With pain & Without pain & Total & \\
\hline With TMD & 14 & 24 & 38 & $p=0.000^{\star}$ \\
\hline Without TMD & 3 & 69 & 72 & $\mathrm{OR}=13.41$ \\
\hline Total & 17 & 93 & 110 & $\begin{array}{c}95 \% \mathrm{Cl}=3.54-50.7 \\
\text { Kappa }=0.37 \\
\text { Sens. }=0.36 \\
\text { Spec. }=0.95 \\
\text { PPV }=82 \% \\
\text { NPV }=74 \%\end{array}$ \\
\hline Clicking & With clicking & Without clicking & Total & \\
\hline With TMD & 24 & 14 & 38 & $p=0.000^{*}$ \\
\hline Without TMD & 13 & 59 & 72 & $\mathrm{OR}=7.78$ \\
\hline Total & 37 & 73 & 110 & $\begin{array}{c}95 \% \mathrm{Cl}=3.19-18.97 \\
\text { Kappa }=0.45 \\
\text { Sens. }=0.63 \\
\text { Spec. }=0.81 \\
\text { PPV }=64 \% \\
\text { NPV }=80 \%\end{array}$ \\
\hline Crepitation & With Crepitation & Without Crepitation & Total & \\
\hline With TMD & 16 & 22 & 38 & $p=0.002^{\star}$ \\
\hline Without TMD & 10 & 62 & 72 & $\mathrm{OR}=4.5$ \\
\hline Total & 26 & 84 & 110 & $\begin{array}{c}95 \% \mathrm{Cl}=1.78-11.4 \\
\text { Kappa }=0.30 \\
\text { Sens. }=0.42 \\
\text { Spec. }=0.86 \\
\text { PPV }=61 \% \\
\text { NPV }=73 \%\end{array}$ \\
\hline NCG & With NCG & Without NCG & Total & \\
\hline With TMD & 12 & 26 & 38 & $p=0.150$ \\
\hline Without TMD & 13 & 59 & 72 & $\mathrm{OR}=2.09$ \\
\hline Total & 25 & 85 & 110 & $95 \% \mathrm{Cl}=0.84-5.2$ \\
\hline DCG & With DCG & Without DCG & Total & \\
\hline With TMD & 10 & 28 & 38 & $p=0.124$ \\
\hline Without TMD & 10 & 62 & 72 & $\mathrm{OR}=2.21$ \\
\hline Total & 20 & 90 & 110 & $95 \% \mathrm{Cl}=0.82-5.92$ \\
\hline
\end{tabular}




\begin{tabular}{|c|c|c|c|c|}
\hline $\mathrm{U} / \mathrm{NHB}$ & With U/NHB & Without U/NHB & Total & \\
\hline With TMD & 23 & 15 & 38 & $p=0.048^{*}$ \\
\hline Without TMD & 29 & 43 & 72 & $\mathrm{OR}=2.27$ \\
\hline Total & 52 & 58 & 110 & $\begin{array}{c}95 \% \mathrm{Cl}=1.01-5.07 \\
\text { Kappa }=0.18 \\
\text { Sens. }=0.60 \\
\text { Spec. }=0.59 \\
\text { PPV }=44 \% \\
\text { NPV }=74 \%\end{array}$ \\
\hline MR & With MR & Without MR & Total & \\
\hline With TMD & 10 & 28 & 38 & $p=0.028^{*}$ \\
\hline Without TMD & 7 & 65 & 72 & $\mathrm{OR}=3.31$ \\
\hline Total & 17 & 93 & 110 & $\begin{array}{c}95 \% \mathrm{Cl}=1.14-9.59 \\
\text { Kappa }=0.19 \\
\text { Sens. }=0.26 \\
\text { Spec. }=0.90 \\
\text { PPV }=58 \% \\
\text { NPV }=69 \%\end{array}$ \\
\hline Tinnitus & With tinnitus & Without tinnitus & Total & \\
\hline With TMD & 18 & 20 & 38 & $p=0.841$ \\
\hline Without TMD & 32 & 40 & 72 & $\mathrm{OR}=1.12$ \\
\hline Total & 50 & 60 & 110 & $95 \% \mathrm{Cl}=0.51-2.47$ \\
\hline
\end{tabular}

Chi-squared test, ${ }^{\star} p<0.05$.

Captions: TMD - Temporomandibular disorder; NCG - nighttime clenching/gnashing; DCG - daytime clenching/gnashing; U/NHB - Uncomfortable/non-habitual bite; MR - Morning rigidity; OR - Odds Ratio; 95\% Cl - Confidence interval; Sens. - Sensitivity; Spec. - Specificity; PPV - positive predictive value; NPV - negative predictive value.

The analysis of the sociodemographic profile and stage of the disease with the TMD predictors revealed no association with age, sex, schooling level, and marital status. Table 3 presents only the significant associations of income and stage of the disease with the following predictors: nighttime clenching/gnashing with $1 / 2$ to 3 minimum wages $(p=0.006)$; tinnitus with stage 1 of the disease $(p=0.02), 1 / 2$ to 3 minimum wages ( $p=0.003$ ), and 4 to 10 minimum wages $(p=$ $0.004)$. Greater sensitivity was obtained in the following associations: nighttime clenching/gnashing with $1 / 2$ to 3 minimum wages (84\%), and tinnitus with $1 / 2$ to 3 minimum wages $(80 \%)$. The highest odds ratio value was verified crossing income with nighttime clenching/ gnashing $(\mathrm{OR}=4.54)$, whereas the other associations ranged from $\mathrm{OR}=0.26$ to 3.74 . 
Table 3. Association of nighttime clenching/gnashing and tinnitus with income and stage of the disease

\begin{tabular}{|c|c|c|c|c|}
\hline \multicolumn{5}{|c|}{ Nighttime clenching/gnashing } \\
\hline Income $1 / 2$ to 3 & With NCG & Without NCG & Total & \\
\hline Yes & 22 & 46 & 68 & $p=0.006^{\star}$ \\
\hline No & 4 & 38 & 42 & $\mathrm{OR}=4.54$ \\
\hline Total & 26 & 84 & 110 & $\begin{array}{c}95 \% \mathrm{Cl}=1.44-14.3 \\
\text { Kappa }=0.19 \\
\text { Sens. }=0.84 \\
\text { Spec. }=0.45 \\
\text { PPV }=32 \% \\
\text { NPV }=90 \%\end{array}$ \\
\hline \multicolumn{5}{|c|}{ Tinnitus } \\
\hline $\begin{array}{l}\text { Stage } 1 \text { of the } \\
\text { disease }\end{array}$ & With tinnitus & Without tinnitus & Total & \\
\hline Yes & 7 & 20 & 27 & $p=0.02^{*}$ \\
\hline No & 43 & 40 & 83 & $\mathrm{OR}=0.32$ \\
\hline Total & 50 & 60 & 110 & $\begin{array}{c}95 \% \mathrm{CI}=0.12-0.85 \\
\text { Kappa }=-0.2 \\
\text { Sens. }=0.14 \\
\text { Spec. }=0.66 \\
\text { PPV }=25 \% \\
\text { NPV }=48 \%\end{array}$ \\
\hline Income $1 / 2$ to 3 & With tinnitus & Without tinnitus & Total & \\
\hline Yes & 40 & 31 & 71 & $p=0.003^{*}$ \\
\hline No & 10 & 29 & 39 & $\mathrm{OR}=3.74$ \\
\hline Total & 50 & 60 & 110 & $\begin{array}{c}95 \% \mathrm{Cl}=1.58-8.82 \\
\text { Kappa }=0.27 \\
\text { Sens. }=0.80 \\
\text { Spec. }=0.48 \\
\text { PPV }=56 \% \\
\text { NPV }=74 \%\end{array}$ \\
\hline Income 4 to 10 & With tinnitus & Without tinnitus & Total & \\
\hline Yes & 8 & 25 & 33 & $p=0.004^{*}$ \\
\hline No & 42 & 35 & 77 & $\mathrm{OR}=0.26$ \\
\hline Total & 50 & 60 & 110 & $\begin{array}{c}95 \% \text { Cl }=0.10-0.66 \\
\text { Kappa }=-0.26 \\
\text { Sens. }=0.16 \\
\text { Spec. }=0.58 \\
\text { PPV }=24 \% \\
\text { NPV }=45 \%\end{array}$ \\
\hline
\end{tabular}

Chi-squared test, ${ }^{*} p<0.05$.

Captions: Income - in minimum wages per month; NCG - nighttime clenching/gnashing; OR - Odds Ratio; $95 \% \mathrm{Cl}$ - Confidence interval; Sens. - Sensitivity; Spec. -

Specificity; PPV - positive predictive value; NPV - negative predictive value 


\section{DISCUSSION}

A higher prevalence of men with PD was observed in this research. This finding agrees with the literature, which points to a higher prevalence of the disease in this $\operatorname{sex}^{21}$. On the other hand, it has been proven that there is a greater predominance of women with $\mathrm{TMD}^{8}$, which may be associated with the role of female hormones (e.g., estrogen) in the modulation of TMD ${ }^{22}$.

Regarding the age group, PD was more present in older adults, confirming research that states that the disease is manifested more frequently in these people ${ }^{23,24}$. Such characteristic corroborates a study that assessed the symptoms of TMD and associated factors in 287 older adults aged 65 to 74 years and found a prevalence of $55 \%$ of people diagnosed with $\mathrm{TMD}^{25}$. As for marital status, most of the subjects were married, similar to an investigation on the clinical-epidemiological profile of people with PD in Salvador, Bahia, Brazil, in which $75 \%$ of them were married ${ }^{26}$.

Regarding schooling level, it was observed that most people had completed high school. In this sense, an investigation on TMD verified that illiterate people are more prone to developing the disorder, as they have a deficient perception of oral health because of their schooling level ${ }^{11}$. The existing differences between social classes have various types of consequences for people's health ${ }^{12}$. This study presented a larger number of people whose income was between $1 / 2$ and 3 minimum wages - similar to the research by Sampaio et al. ${ }^{27}$, who associate the income of institutionalized older adults and reveal a higher prevalence of TMD among people in this income range.

Regarding the stage of the disease, a higher prevalence was observed in those in stage 2. This aspect agrees with a recent study, which reported a greater presence of TMD in this stage ${ }^{23}$. Likewise, Bakke et al. ${ }^{28}$ proved that orofacial function and oral health decreased as the disease increased in severity. The time since diagnosis was not associated with TMD. However, a study on people with PD verified that being in the first year after diagnosing the disease increase the likelihood of developing TMD and, in the long run (> 5 years), there is an increased risk of developing this disorder ${ }^{29}$.

Pain was considered a predictor for TMD because of its association with the disorder ${ }^{30}$. Thus, people with PD who also have pain are 13.41 times more likely to manifest TMD than those who do not feel pain. This aspect was observed in the higher PPV (82\%), in which people who had a positive result in the pain test had TMD. Hence, the present study corroborates the statement that chronic pain is associated with TMD in people with $\mathrm{PD}^{31}$.

In this study, an uncomfortable/non-habitual bite was a predictor with a significant association. It was observed that people that reported this clinical sign were 2.27 times more likely to develop TMD. Such a particularity differs from a recent investigation with a similar sample, which observed that uncomfortable/ non-habitual bite was not related to $\mathrm{TMD}^{16}$. It agrees, though, with Trize et al. ${ }^{32}$ in a study involving 102 people aged 19 to 86 years and using the RDC/TMD to reach a diagnosis; they assessed that discomfort when biting is significantly associated with TMD.

Crepitation is a prevalent symptom in the disorder, more often in the severest TMJ degenerations ${ }^{33}$. This study verified that people with PD were 4.5 times more likely to develop it. A similar result was verified by Silva et al. ${ }^{16}$ in the association of some of the disorder's clinical signs with PD, presenting crepitation as a factor associated with TMD $(p=0.004)$. Clicking has already been observed in research with 4,204 medical records of patients whose mean age was 53.99 years, in which the prevalence was $14.8 \%^{34}$. In this study, it was observed that the presence of such a TMJ clinical sign implies being 7.78 times more likely to manifest TMD. Also, lodice et al. ${ }^{35}$ assessed the prevalence of TMD and joint noises in adults and found, in a sample of 4,299 people, $30.7 \%$ with TMJ clicking and $10.3 \%$ with crepitation, confirming the presence of these sounds in TMD.

Morning rigidity is present in PD because of muscle inflexibility ${ }^{36}$. It was verified in this study that this type of rigidity makes these patients 3.31 times more likely to have TMD. This can influence their vertical mouth opening due to rigidity of the masseter and temporal muscles, in chewing, and in the relationship between the TMJ and the stomatognathic system ${ }^{37}$.

Of the different associations made, sociodemographic profiles with predictors for TMD, age, sex, schooling level, and marital status were not significant for findings regarding TMD. However, income and stage of the disease with nighttime clenching/gnashing and tinnitus had significant relationships to investigate TMD.

It has been proved that those who have the parafunctional habit of nighttime clenching/gnashing with an income of $1 / 2$ to 3 minimum wages are 4.54 times more likely to develop the disorder. This relationship between TMD and nighttime clenching/gnashing was 
also observed in another cross-sectional study with 172 subjects 17 to 78 years old, which reports the habit of gnashing the teeth at night in $47 \%$ of the sample ${ }^{38}$. It is also important to highlight that belonging to lower social classes causes a high stress level due to the presence of risk groups and higher violence and mortality rates ${ }^{12}$.

The people's financial situation was associated with the presence of tinnitus. In this study, this finding was observed in relation to the income of $1 / 2$ to 3 minimum wages, revealing that the likelihood of having TMD increases 3.74 times when both variables are present. It is known that tinnitus has been frequently found in people with TMD and that it can already be a risk factor for this disorder ${ }^{10,39}$. Despite the positive results between TMD and tinnitus as a predictor, its explanation is still debated and difficult to understand ${ }^{40}$.

This study has limitations, as it does not enable causality to be verified. It is suggested that, in future research, income be assessed with a more specific tool, such as the Brazil Economic Classification Criteria used by the Associação Brasileira de Empresas de Pesquisa (Brazilian Association of Research Companies, ABEP). Moreover, longitudinal studies should be conducted to better observe the cause-and-effect relationships between PD and TMD and enrich the debate on this issue.

\section{CONCLUSION}

In this study, the predictors associated with TMD in people with PD were pain, clicking, crepitation, uncomfortable/non-habitual bite, and morning rigidity. It was also verified that income and stage 1 of the disease had an association with nighttime clenching/gnashing and tinnitus.

\section{ACKNOWLEDGMENTS}

The present paper was financed, in part, by the Coordenação de Aperfeiçoamento de Pessoal de Nível Superior - Brasil (CAPES) - Finance Code 001.

\section{REFERENCES}

1. Organização Mundial de Saúde. Relatório Mundial de Envelhecimento e Saúde. Estados Unidos. 2015.

2. Collier TJ, Kanaan NM, Kordower JH. Aging and Parkinson's disease: different sides of the same coin? Mov Disord. 2017;32(7):983-90.
3. Baker DJ, Peterson RC. Cellular senescence in brain aging and neurodegenerative diseases: evidence and perspectives. J Clin Invest. 2018;128(4):1208-16.

4. Kandel ER, Schwartz JH, Jesell TM, Siegelbaum AS, Hudspeth AJ. Princípios da Neurociências. 5rd ed. São Paulo: AMGH; 2014.

5. Souza CF, Almeida HC, Souza JM, Costa PH, Silveira YSS, Bezerra JCL. A doença de Parkinson e o processo de envelhecimento motor: uma revisão de literatura. Rev Neurocienc. 2011;19(4):718-23.

6. Nascimento ICB, Santos RCO, Guerreiro CF, Cista ACN, Camelier FWR. Avaliação postural em pessoas com doença de Parkinson. RPF. 2016;6(1):56-64.

7. Olmos SR, Kritz-Silverteins D, Halligan W, Silverstein ST. The effect of condyle fossa relationships on head posture. Cranio. 2005;23(1):48-52.

8. Yadav S, Yang Y, Dutra EH, Robinson JL, Wadhwa S. Temporomandibular joint disorders in the elderly and aging population. J Am Geriatric Soc. 2018;66(6):1213-7.

9. Wadhwa S, Kapila S. TMJ disorders: future innovations in diagnostics and therapeutics. J Dent Educ. 2008;72(8):930-47.

10. Faccio PF, Santos MAB, Silva TAM, Moretti EC, Coriolano MGWS, Lins CCSA. Factors associated with temporomandibular dysfunction in the elderly: an integrative literature review. Rev. bras. geriatr. Gerontol. 2019;22(1):1-11.

11. Silva TVA, Coriolano MGWS, Lins CCSA. Temporomandibular joint dysfunction in Parkinson's disease: an integrative literature review. Rev. CEFAC. 2017;19(5):702-11.

12. Cavalcanti MOA, Lima CCM, Lima JMC, Gomes I, Goldim JR. Prevalência da disfunção temporomandibular em idosos não institucionalizados. Estud. Interdiscipl. Envelhec. 2015;20(2):551-6.

13. Martins RJ, Garcia AR, Garbin CAS, Sundefeld MLMM. Association between economic class and stress in temporomandibular joint dysfunction. Rev Bras Epidemiol. 2007;10(2):215-22.

14. Chaves TC, Oliveira AS, Grossi DB. Main instruments for assessing temporomandibular disorders, part II: diagnostic criteria; a contribution to clinicians and researchers. Fisioter. Pesqui. 2008;15(1):101-6. 
15. Gonçalves DG, Gama MCS, Rizzatti-Barbosa CM, Pereira Jr FJ. Critérios de diagnóstico para desordens temporomandibulares: Protocolo Clínico e Instrumentos de Avaliação Brazilian Portuguese. International Network for orofacial Pain and Related Disorders Methodology. 2020. Disponivel em: https://ubwp.buffalo.edu/ rdc-tmdinternational/tmd-assessmentdiagnosis/ dc-tmd/dc-tmd-translations/.

16. Silva TVA, Sobral AV, Silva RM, Almeida VLS, Coriolano MGWS, Lins CCSA. Pain, click and crepitation as factors associated with temporomandibular dysfunction in Parkinson's disease. Br J Pain. 2018;1(3):248-54.

17. Bertolucci PHF, Brucki SMD, Campacci SR, Juliano Y. The Mini-Mental State Examination in an outpatient population: influence of literacy. Arq. Neuropsiquiatr. 1994;52(1):1-7.

18. Lucena LBS, Kosminky M, Costa LJ, Góes PSA. Validation of the Portuguese version of the RDC/ TMD Axis II questionnaire. Braz Oral Res. 2006;20(4):312-7.

19. Sousa MR, Ribeiro ALP. Systematic review and meta-analysis of diagnostic and prognostic studies: a tutorial. Arq Bras Cardiol. 2009;92(3):241-51.

20. Perroca MG, Gaidzinski RR. Assessing the interrater reliability of an instrument for classifying patients kappa quotient. Rev Esc Enferm. 2003;37(1):72-80.

21. Elbaz A, Carcailloon L, Kab S, Moisan F. Epidemiology of Parkinson's disease. Revue Neurologique. 2016;172(1):14-26.

22. Robinson JL, Johnson PM, Kister K, Yin MT, Chen J, Wadhwa S. Estrogen signaling impacts temporomandibular joint and periodontal disease pathology. Odontology. 2020;108(2):153-65.

23. Silva RM, Santos VL, Silva TVA, Lins CCSA. Prevalence of temporomandibular joint disorder in people with Parkinson's disease in a public university hospital. Rev. CEFAC. 2019;21(3):e17618.

24. Martins NIM, Asano NMJ, Lins CCSA, Coriolano MGWS. Demographic and clinical variables as differentiating predictors of cognitive disorders in Parkinson's disease. Rev. bras. geriatr. gerontol. 2019;22(1):e180141.

25. Czernaik CM, Muniz FWMG, Colussi PRG, Rosing CK, Colussi EL. Association between temporomandibular disorder symptoms and demographic, dental and behavioral factors in the elderly: a population-based cross-sectional study. Br J Pain. 2018;1(3):223-30.
26. Fernandes I, Filho ASA. Estudo clínicoepidemiológico de pacientes com doença de Parkinson em Salvador-Bahia. Rev. Bras. neurol. Psiquiatr. 2018;22(1):45-59.

27. Sampaio NM, Oliveira MC, Ortega AO, Santos LB, Alves TDB. Temporomandibular disorder in elderly individuals: the influence of institutionalization and sociodemografic factors. CoDAS. 2017;29(2):e20160114.

28. Bakke M, Larsen SL, Lautrup C, Karlsborg M. Orofacial function and oral health in patients with Parkinson's disease. Eur $J$ Oral Sci. 2011;119(1):27-32.

29. Chen Y-Y, Fan H-C, Tung M-C, Chang Y-K. The association between Parkinson's disease and temporomandibular disorder. PloS One. 2019;14(6):e0217763.

30. Fehrenbach J, Silva BSG, Brondani LP. A associação da disfunção temporomandibular à dor orofacial e cefaleia. JOI. 2018;7(2):69-78.

31. Faccio PF, Tavares RB, Asano NMJ, Asano AGC, Coriolano MGWS, Lins CCSA. Chronic pain and depression as factors associated with temporomandibular dysfunction in older adults with Parkinson's disease. Rev. CEFAC. 2020;22(4):e7719.

32. Trize DM, Calabria MP, Franzolin SO, Cunha CO, Marta SN. Is quality of life affected by temporomandibular disorders? Einstein. 2018;16(4):1-6.

33. Motta LJ, Silva PFC, Godoy CHL, Bortoletto CC, Garcia PRAG, Silva FC et al. Assessment of temporomandibular joint sounds in children with bruxism. Rev. CEFAC. 2015;17(1):111-5.

34. Chatzopoulos GS, Sanchez M, Cisneiros A, Wolff LF. Prevalence of temporomandibular symptoms and parafunctional habits in a university dental clinic and association with gender, age, and missing teeth. CRANIO. 2017;37(3):159-67.

35. Iodice G, Cimino R, Vollaro S, Lobbezoo F, Michelotti A. Prevalence of temporomandibular disorder pain, jaw noises and oral behaviours in an adult Italian population sample. J Oral Rehabil. 2019;46(8):691-8.

36. Steidl EMS, Ziegler JR, Ferreira FV. Doença de Parkinson: revisão bibliográfica. Disc. Scientia. 2007;8(1):115-29. 
37. Bento FAM, Diaféria GLA, Fonoff ET, Padovani MMP, Behlau M. Effect of overarticulation technique in voice and speech os individuals with Parkinson's disease with deep brain stimulation. Audiol., Commum. Res. 2019;24:e2008.

38. Bortolleto PPB, Moreira APSM, Madureira PR. Analyses parafunctional habits and association with Temporomandibular Disorder. Rev Assoc Paul Cir Dent. 2013;67(3):216-21.

39. Mottaghi A, Menéndez-Díaz I, Cobo JL, GonzálezSerrano J, Cobo T. Is there a higher prevalence of tinnitus in patients with temporomandibular disorders? A systematic review and meta- analysis. J Oral Rehabil. 2019;46(1):76-86.

40. Dermikol N, Dermikol M, Usumez A, Sari F, Akcaboy C. The potential etiologic factors influencing tinnitus intensity in patients with temporomandibular disorder. Cranio. 2018;36(6):360-5. 